\title{
Postseismic deformation and body forces shaping the Apennines and adjacent sedimentary basins in Umbria-Marche
}

\author{
Riccardo E.M. Riva $\left({ }^{1}\right)$ and Abdelkrim Aoudia $\left({ }^{2}\right)$ \\ ( ${ }^{1}$ ) Dept. of Earth Observation and Space Systems, Delft University of Technology, Delft, The Netherlands \\ $\left.{ }^{(}\right)$Earth System Physics Section, the Abdus Salam International Centre for Theoretical Physics, Trieste, Italy
}

\begin{abstract}
The geodynamic complexity of the Apennines and adjacent sedimentary basins in Umbria-Marche (North-Central Italy) makes the dynamics of the present day deformation and its relationships with the seismicity less well understood. In this paper, we argue that, further to buoyancy forces, postseismic deformation of earthquakes taking place on the Apennines contributes to the regional deformation. We investigate the interaction between the normal faulting system responsible of the 1997 Umbria-Marche earthquake sequence (Colfiorito fault) and the low angle normal faulting system bordering the sedimentary basins, namely the Altotiberina fault. We set-up a 2D finite element model of the lithosphere-asthenosphere accounting for lateral heterogeneities and investigate how this heterogeneous structure is capable of localizing strain under the Umbria-Marche sedimentary basins, providing a way for the Colfiorito fault to influence the evolution of the Altotiberina fault. We show how the two different length and time scale processes, namely postseismic deformation and buoyancy, are complementary in shaping the Apennines and adjacent sedimentary basins. The high resolution deformation patterns modeled in this study can hardly be reproduced by a model accounting only for external forces such as a rotating or subducting or retreating Adria.
\end{abstract}

Key words Viscoelastic relaxation - Aseismic slip - Body forces - Normal faults

\section{Introduction}

The geodynamic complexity of the Apennines and adjacent sedimentary basins in Umbria-Marche (North-Central Italy) makes the dynamics of the present day deformation and its relationships with the seismicity less well understood. The recent 1997-1998 Umbria-Marche

Mailing address: Dr. Riccardo E.M. Riva, Dept. of Earth Observation and Spaces System, Delft University of Technology, Kluyverweg 1, 2629 HS Delft, The Netherlands; e-mail: r.e.m.riva@tudelft.nl earthquake sequence clearly highlighted complex deformation processes both in its coseismic (e.g. Amato et al., 1998; Zollo et al., 1999; Salvi et al., 2000; Chimera et al., 2003) and postseismic (Riva et al., 2000; Aoudia et al., 2003; Riva et al., 2007) phases. The Umbria-Marche crustal normal faulting seismic sequence, which consisted of three moderate earthquakes (26/09/97 at 00:33, $\mathrm{M}_{\mathrm{W}}=5.7 ; 26 / 09 / 1997$ at $09: 40, \mathrm{M}_{\mathrm{W}}=6.1$ and $14 / 10 / 1997$ at $15: 23, M_{\mathrm{w}}=5.6$ ), ruptured three distinct fault segments (e.g., Galadini et al., 1999; Meghraoui et al., 1999; Barba and Basili, 2000). In the same region an earthquake occurred in the upper mantle, on March 28, 1998, $\mathrm{M}_{\mathrm{W}}=5.2$ (e.g., Olivieri and Ekstrom, 1999; Chimera et al., 20003) highlighting the importance of deep processes in the lithosphere. The lithosphere velocity models beneath Central Italy clearly highlighted the important lateral heterogeneity of the physical properties of the crust-uppermost mantle system along with pronounced variations of the 
geometry of both the crust-mantle and lithosphere-asthenosphere boundaries (e.g. Agostinetti et al., 2002; Chimera et al., 2003; Mele and Sandvol, 2003). These models exhibit clear evidence of lithospheric roots without any continuous slab. This would imply that the slab has been eroded and no engine is actually left to drive relative subduction processes. Therefore our favorite model of the dynamics of the ongoing continental deformation is the one reported by Aoudia et al. (2007) that invokes body forces instead of external forces to satisfy the recent kinematics. Aoudia et al. (2007) have shown that the buoyancy forces resulting from the heterogeneous density distribution in the lithosphere govern the present day deformation within Central Italy and can explain regional coexisting contraction and extension at shallow depth and unusual distribution of sub-crustal earthquakes. Their modeled uppermost mantle flow supports the lithospheric delamination beneath the peninsula and provides a unifying background for petrologic and geochemical studies of recent magmatism and volcanism in Tuscany.

Further to the buoyancy forces already reported in Aoudia et al. (2007), this paper argues that postseismic deformation of earthquakes taking place on the Apennines contributes to the regional deformation. We investigate the interaction between the normal faulting system responsible for the 1997 Umbria-Marche earthquake sequence (Colfiorito fault, CF) and the low angle normal faulting system bordering the sedimentary basins, namely the Altotiberina fault (AF) (e.g. Boncio and Lavecchia, 2000; Chiaraluce et al., 2007). By means of a half-space model we investigate the effect on the CF of prolonged slip on the AF. After that, we set-up a 2D finite element model of the lithosphere-asthenosphere accounting for lateral heterogeneities and investigate how this heterogeneous structure is capable of localizing strain under the Umbria-Marche sedimentary basins, providing a way for the $\mathrm{CF}$ to influence the evolution of the AF.

\section{Secular postseismic relaxation}

When approaching the study of postseismic deformation in the area of the 1997 Colfiorito earthquake, different mechanisms have to be taken into account (e.g. viscoelastic relaxation, afterslip, poroelastic relaxation...). Here, we are not interested in the details of present day relaxation (see, e.g., Riva et al., 2007): instead, we want to estimate the cumulative impact of viscoelastic relaxation due to repeated seismic events in the area. According to historical records (Boschi et al., 2000), the largest events that occurred in the direct neighborhoods of the Colfiorito fault (CF) are the 1279 Camerino in the north and the 1328 Norcia in the south, with magnitudes 6.6 and 6.2 respectively.

We model the cumulative effect of those two earthquakes by means of a 50-km-long normal fault rupturing at a depth of $8 \mathrm{~km}$ and dipping 45 degrees to the SW, which approximately corresponds to an extension of the main fault of the 1997 sequence by $15 \mathrm{~km}$ to the north and $25 \mathrm{~km}$ to the south. The moment magnitude is equivalent to the cumulative effect of a 6.6 and 6.2 event $\left(\mathrm{M}_{0}=6 \times 10^{18} \mathrm{Nm}\right)$. The full relaxation of this fault is modeled by means of a normal modes approach (Sabadini and Vermeersen, 1997), with a stratified earth model comprising a 15-km elastic upper crust, a Moho at $30 \mathrm{~km}$, a 20-km-thick mantle wedge and a homogeneous mantle. Since we discuss the fully relaxed model (i.e. at infinite time), the viscosity profile which controls the temporal variations of the relaxation process is here irrelevant, the key earth parameter being the thickness of the upper elastic layer.

Results for vertical relaxation are shown in fig. 1, where the thin solid lines describe the surface projection of the boundaries of the three main patches that represent the Altotiberina fault (AF) (Boncio and Lavecchia, 2000), starting at the surface in the SW and dipping towards the NE, and smaller open rectangles represent the surface projections of the three main faults of the 1997 sequence (from the north: the 9:40 event on 26 Sept., the 0:33 event on 26 Sept, and the Sellano event on 14 Oct.). We see how the whole area between the CF and the surface expression of the AF is dominated by subsidence: it is noteworthy; that in the same area we find deep sedimentary basins and most of the spread microseismicity observed in the Umbria-Marche Apennines (Deschamps et al., 


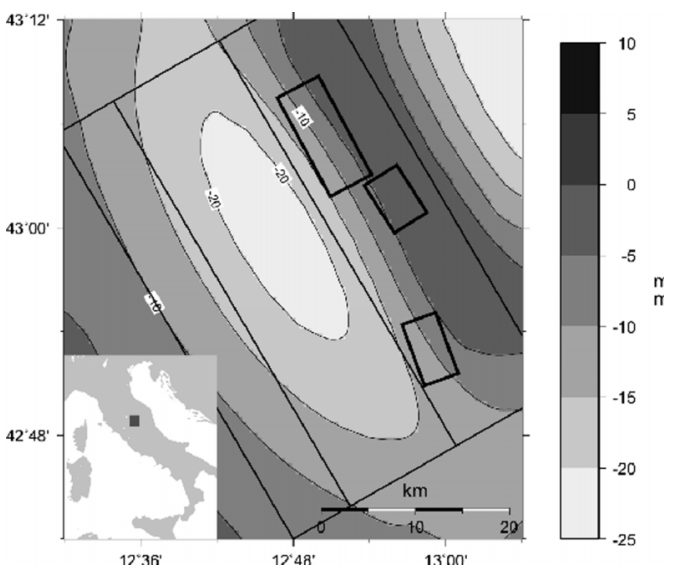

Fig. 1. Vertical postseismic relaxation due to slip on a 50-km-long normal fault, dipping 45 degrees to the SW and representing a prolongation of the largest shock of the 1997 sequence (northernmost open box). The three small open boxes represent the surface projections of largest shocks of the 1997 sequence, while the large boxes with bounded by thin lines represent the three segments of the Altotiberina fault.

1989). The maximum deformation amounts to about $22 \mathrm{~mm}$, providing a secular rate of 0.03 $\mathrm{mm} / \mathrm{a}$ if we assume a recurrence time of $700 \mathrm{a}$, as suggested by Pantosti et al. (1999) after interpreting the 1997 sequence as a reoccurrence of the 1279 earthquake. Since the upper crust has brittle properties, modeled vertical relaxation at the surface is representative of the displacement of the whole seismogenic layer. Therefore, we can project the vertical motion onto the AF to obtain average slip rates between $0.02 \mathrm{~mm} / \mathrm{a}$ and $0.12 \mathrm{~mm} / \mathrm{a}$, which are much smaller than the value of $1 \mathrm{~mm} / \mathrm{a}$ suggested by Chiaraluce et al. (2007) for the northern segment of the AF.

The average slip rates we have computed are meant to represent the long term effect of the $\mathrm{CF}$ relaxation on the evolution of the AF. Therefore, we are not interested in a detailed description of the relaxation process, which would have to take into account additional factors such as time-variable relaxation and nearly-free shear stress conditions on the AF. Depending on the viscosity profile, deformation rates in the first few years after each earthquake can easily reach values of several millimeters per year, as we discuss in a later section. Moreover, allowing the AF to slip under specific conditions would surely have an impact on the stress evolution within the upper crust that we have here modeled as a continuous elastic layer. However, the use of a more sophisticated model would not have a strong impact on the purpose of this section, i.e. showing that relaxation of the CF is capable to load the AF, but it cannot represent the primary loading mechanism.

\section{Slip on the Altotiberina fault}

Since it appears that the average rates of postseismic relaxation due to earthquakes in the Colfiorito area account for only a small fraction of the AF slip, here we explore the possibility of an opposite interaction, namely an active role of the AF in the evolution of the UmbriaMarche fault zone. For this purpose, we model co- and post-sesimic deformation due to a 50km-long NE-dipping normal fault representing the AF. Following Boncio and Lavecchia (2000), we distinguish three fault patches along the dip, with the shallowest (0-4 km depth) and deepest (7-14 km depth) patches dipping $30^{\circ}$ and the middle patch dipping $13^{\circ}$. We model the coseismic response by means of a half-space model (Feigl and Dupre, 1998) and viscoelastic relaxation as in the previous section.

Figure 2 shows the total (elastic plus full relaxation) vertical deformation due to $70 \mathrm{~cm}$ of slip on the AF, consistent with a rate of $1 \mathrm{~mm} / \mathrm{a}$ (Chiaraluce et al., 2007) during a 700-year seismic cycle (Pantosti et al., 1999). The whole area under the AF is dominated by subsidence, with a maximum due to the elastic component where the AF intersects the free surface and a second maximum due to viscoelastic relaxation below the CF. The large subsidence below the $C F$ reaches a value of about $35 \mathrm{~cm}$, comparable with the average slip accommodated on the largest faults during the recent 1997 sequence (Zollo et al., 1999), suggesting that the $\mathrm{AF}$ is capable of actively loading the $\mathrm{CF}$ throughout a seismic cycle. 


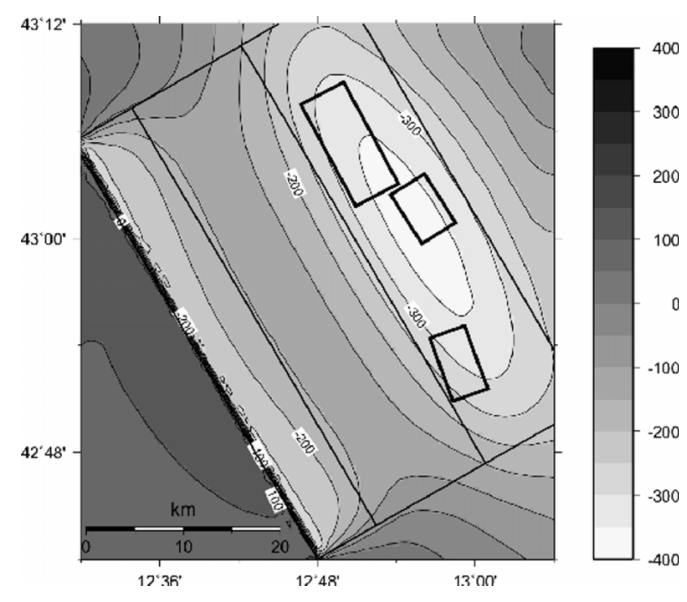

Fig. 2. Vertical deformation (elastic plus full relaxation) due to $70 \mathrm{~cm}$ of slip on the Altotiberina fault (AF). The large black boxes represent the three segments of the Altotiberina fault, dipping towards the $\mathrm{NE}$ with angles of $30^{\circ}, 13^{\circ}$ and $30^{\circ}$ (shallow, middle and deep segment respectively). The three small boxes represent the surface projections of the largest shocks of the 1997 sequence.

\section{Postseismic relaxation with a lateral heterogeneous lithosphere}

The first part of our study focused on the average features of postseismic relaxation after earthquakes on the CF. The purpose of the present section is to discuss an improved postseismic relaxation model consistent with lateral crustal variations present in the Central Apennines.

By means of a 2D finite elements approach (Govers and Wortel, 1995), we model a SW-NE section through the Central Apennines extending for $250 \mathrm{~km}$ at each side of the $\mathrm{CF}$, where the domain size has been chosen to minimize the effect of boundary conditions on the area of interest. Lateral variations are introduced according to the results published by Chimera et al. (2003). A large level of heterogeneity characterizes the topography of the Moho, which is located at a depth of $30 \mathrm{~km}$ under the CF area and at $38 \mathrm{~km}$ under the Adriatic Sea, whereas on the left side it presents a minimum of $28 \mathrm{~km}$ west of the AF and finally deepens to $33 \mathrm{~km}$ towards the Tuscan domain. According to Chimera et al. (2003), a 20-km-thick layer of hot lithospheric material, called mantle wedge, underlies the Moho beneath the Tuscan magmatic complex and one large part of the Central Apennines. This layer dies out before reaching the Adriatic coast, where a colder thermal profile is expected is also observed by heat flow studies (Della Vedova et al., 2000). In our model domain, the two end members are represented by the Tuscan magmatic domain on the left, with a thin lithospheric lid leading to high temperature and low viscosities, and the Adriatic domain at the right side, with a thick lithospheric lid and a consequent cold isotherm and high viscosities. In the middle of the domain, under the $\mathrm{CF}$ and $\mathrm{AF}$, the presence of the hot mantle wedge induces low viscosities also in the lower crust, even if the area is located above thick lithospheric roots. We impose a laterally varying temperature profile consistent with the lithospheric structure and with the observed heat flow, and let the viscosity profile be controlled by empirical flow laws for rocks and by laboratory derived rheological parameters (e.g., Ranalli, 1995). Since we have a large choice of possible rheologies and stress conditions, we have introduced an additional constraint by looking for those combinations of rheology and stress that provide viscosities anywhere not lower than $10^{17} \mathrm{~Pa} \mathrm{~s}$ at the bottom of the lower crust and $10^{16} \mathrm{~Pa} \mathrm{~s}$ in the mantle wedge. A viscosity of $10^{17} \mathrm{~Pa} \mathrm{~s}$ at the bottom of the lower crust is consistent with laboratory rheological parameters for soft lower crustal materials (e.g. wet diorite in Hansen and Carter, 1982) under realistic conditions in regions of active tectonics, with a surface heat flow of $60-70 \mathrm{~mW} / \mathrm{m} 2$ and a background stress of 10-100 MPa. In the mantle wedge, the presence of low viscosities is inferred from the very low seismic velocities (VS less than $4.2 \mathrm{~km} / \mathrm{s}$ ), suggesting that the wedge might represent a partially molten mantle (Chimera et al., 2003; Aoudia et al., 2007). With our approach, we aim to represent a plausible viscosity structure, where the choice of different parameters would influence the actual values, but not the relative horizontal viscosity variations, which represent our main point of interest.

Figure 3 , shows the resulting postseismic strain rates one year after the Colfiorito main shock, where the horizontal axis is centered at 


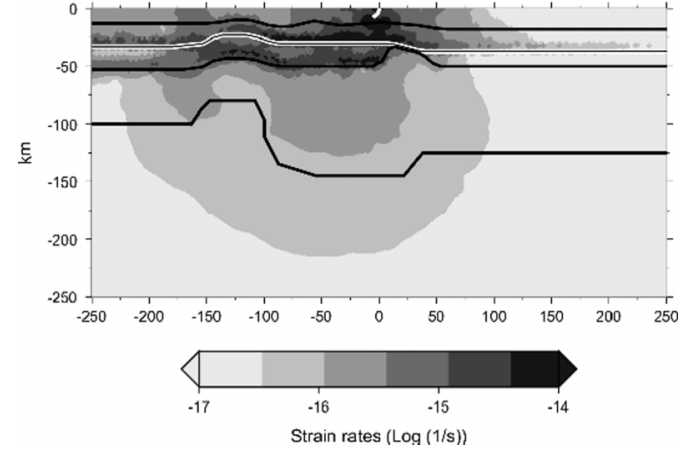

Fig. 3. 2D section through the Central Apennines, showing postseismic strain rates at 1 year after the earthquake. The Colfiorito Fault (CF) is represented by the small white segment in the center of the domain, and the Moho by the thin black line bounded in white.

the $\mathrm{CF}$ and the fault is represented by a small white segment. The two top layers represent the crust (upper and lower), the third layer the mantle wedge, followed by the rest of the lithosphere and by the asthenosphere. The Moho is indicated by a black line bounded in white. We can clearly see how the highest strain rates are localized in three distinct regions: in the first few kilometers around the fault, and in the bottom part of both the lower crust and the mantle wedge. The high strain rates in the upper crust are mainly due to the very large differential stresses induced by the earthquake, while localization of strain rates in the other layers is mainly controlled by the viscosity profile. The combined effect of viscosity jumps at the Moho and at the base of the mantle wedge due to changes in rheology, and lateral viscosity variations driven by the thermal structure, leads to the localization of postseismic relaxation in a confined region below the Umbria-Marche Apennines.

Vertical postseismic relaxation is shown in fig. 4 for the first 10 years after the earthquake: the choice of representing this particular timespan is due to the fact that large portions of the lower crust and mantle wedge have viscosities lower than $10^{19} \mathrm{~Pa} \mathrm{~s}$, meaning that they almost completely relax in the first few years. The upper panel shows viscoelastic relaxation for the

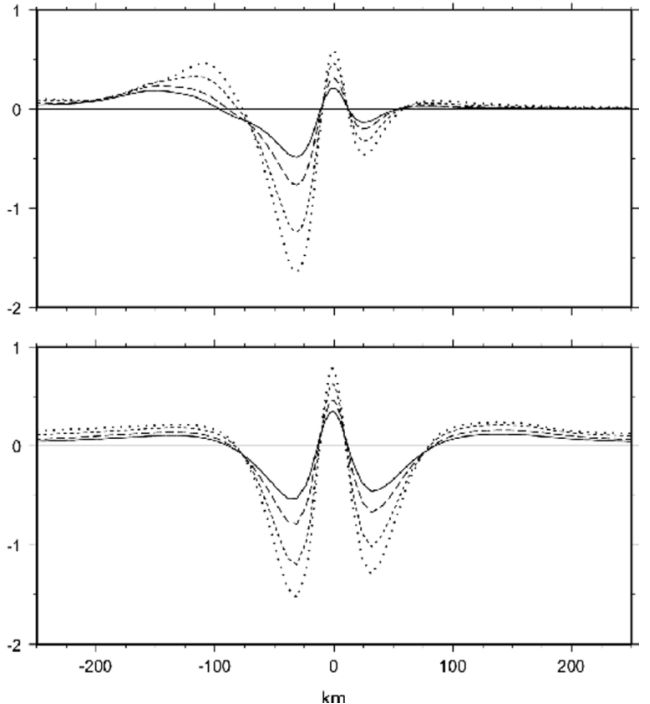

Fig. 4. Postseismic relaxation for the $2 \mathrm{D}$ approximation of the CF for both the lateral heterogeneous (top panel) and the homogeneous (bottom panel) model. The four lines depict vertical deformation at four different times after the earthquake: $t=1$ a (solid), 2 a (long dashed), 5 a (short dashed) and $10 \mathrm{a}$ (dotted).

lateral heterogeneous model, while the bottom panel shows the same result for a lateral homogeneous model with the same structure as the region below the AF. For the case of the heterogeneous model, the deformation pattern is dominated by a large subsidence in a rather narrow region between $10 \mathrm{~km}$ and $75 \mathrm{~km}$ west of the $\mathrm{CF}$, bounded by a narrow uplifting region around the $\mathrm{CF}$ and by a broader uplift further to the west. The large subsidence occurs where large sedimentary basins such as the Foligno basin are mapped. These sedimentary basins are bordered by low-angle normal faults. The effect of lateral heterogeneities is mainly visible in the eastern side: when approaching the colder Adriatic domain, we observe a drastic reduction in subsidence with respect to the homogeneous model. A further difference between the two models is visible towards the Tuscan domain, where the combined effect of the thinner crust and very warm geotherm leads to an amplification of the uplifting bulge. According to those 
results, we think that a lateral heterogeneous lithospheric structure has the effect of localizing postseismic relaxation due to earthquakes in the Colfiorito area in a rather narrow region below the $\mathrm{AF}$ and the related sedimentary basins.

We have verified that our conclusions are not dependent on the adopted 2D approximation, because there is no substantial qualitative difference between relaxation of a 50-km-long fault, representative of multiple ruptures in the Colfiorito area between Camerino and Norcia, and that of an infinitely long fault. The key parameter controlling the wavelength of the relaxation signal, in fact, is represented by the thickness of the upper elastic layer, which is here about $15 \mathrm{~km}$ and therefore much shorter than the extended CF. By comparing relaxation in a vertically layered medium for finite faults of different length, we have further verified that the quantitative effect of the $2 \mathrm{D}$ approximation results in the amplification of the magnitudes of relaxation by about a factor of two, which is again not relevant for the purpose of this study.

\section{Discussion and conclusions}

Here elaborate further on the possibility of an interaction between the low-angle NE-dipping Altotiberina fault (AF) and the SW normal faulting structures responsible for the 1997 Colfiorito sequence. With loose constraints on the magnitude and location of historical earthquakes, as well as on their recurrence time, we have modeled a possible scenario of postseismic relaxation which appears to be consistent that the formation of major sedimentary basins at the western side of the Umbria-Marche faulting zone. The location of the postseismic relaxation signal favours the loading of the AF, even if the slip rates that we have obtained are rather small: however, uncertainties are very large because those values are directly dependent on the average earthquake magnitude and recurrence time.

On the other hand, after modeling the effect of slip on the AF, we have shown that the AF alone could be responsible for providing most of the load necessary to rupture the CF.
When we compare average postseismic relaxation rates due to the $\mathrm{CF}$ with slip rates on the AF, the latter appears to provide the dominating signal. However, for a realistic viscosity structure where the lower crust and the mantle wedge below the Umbria-Marche Apennines are characterized by low viscosities (in the range $10^{16}-10^{18} \mathrm{~Pa} \mathrm{~s}$ ), about half of the total postseismic relaxation is likely to take place in the first 10 years after the earthquake. This means that, at least locally, the postseismic loading on the AF could easily exceed the average slip rates. In addition, the impact of stress relaxation on the evolution of the AF can be increased by the presence of large lateral heterogeneities in the lithospheric structure, which have the effect of concentrating postseismic relaxation below the AF.

In conclusion, a possible scenario for the interaction between the AF and the $\mathrm{CF}$ allows aseismic slip on the AF to effectively load the $\mathrm{CF}$, while postseismic relaxation after each rupture event on the CF plays the role of a feedback process, reloading sections of the AF on short time-scales and potentially affecting the evolution of the AF itself.

From a regional perspective, the strain pattern retrieved from the $2 \mathrm{D}$ finite element modeling of the postseismic deformation mimics the modeled stress pattern that accounts only for buoyancy forces as reported by Aoudia et al. (2007) along the same section and using the same geometry of the crust upper mantle. In fact the realistic pattern of localized vertical deformation reported in fig. 4 compares fairly well with its equivalent part reported in Aoudia et al. (2007, fig. 3). This is evidence that the two different length and time scale processes, namely, postseismic deformation and buoyancy, are complementary in shaping the Apennines and adjacent sedimentary basins. The high resolution deformation patterns modeled in this study as well as the one reported in Aoudia et al. (2003) satisfying the ongoing observed and complex geodynamics across North Central Italy with emphasis to the Umbria-Marche region can hardly be reproduced by a model accounting only for external forces such as a rotating or subducting or retreating Adria. 


\section{Acknowledgements}

This work was done in the framework of the SISMA- Italian Space Agency - Project. We thank Rob Govers for the use of the FEM software GTECTON and two anonymous reviewers for their constructive comments.

\section{REFERENCES}

Agostinetti, N.P., F. P. Lucente, G. Selvaggi and M. Di BONA (2002): Crustal structure and Moho geometry beneath the Northern Apennines (Italy), Geophys. Res. Lett., 29.

Amato, A., R. Azzara, C. Chiarabba, G.B. Cimini, M. Cocco, M. Di Bona, L. Margheriti, S. Mazza, F. Mele, G. Selvaggi, A. Basili, E. Boschi, F. Courboulex, A. Deschamps, S. Gaffet, G. Bittarelli, L. Chiaraluce, D. Piccinini and M. Ripepe (1998): The 1997 Umbria-Marche, Italy, earthquake sequence: a first look at the main shocks and aftershoks, Geophys. Res. Lett., 25 (15), 2861-2864.

Aoudia, A., A.T. Ismail-ZADEH and F. Romanelli (2007): Buoyancy-Driven Deformation and Contemporary Tectonic Stress in the Lithosphere beneath Central Italy, Terra Nova, 19 (6), 490-495, doi: 10.1111/j.1365-3121.2007.00776.x

Aoudia, A., A. Borghi, R. Riva, R. BARZaghi, B.A.C. AmBrosius, R. SABAdini, L.L.A. Vermeersen and G.F. PANZA (2003): Postseismic deformation following the 1997 Umbria-Marche (Italy) moderate normal faulting earthquakes, Geophys. Res. Lett., 70, 1390-1393.

BARBA, S., and R. BASILI (2000): Analysis of seismological and geological observations for moderate-size earthquakes: the Colfiorito Fault System (Central Apennines, Italy), Geophys. J. Int., 141, 241-252.

Boncio, P., and G. LAVECCHIA (2000): A geological model for the Colfiorito earthquakes (September-October 1997, central Italy), Journal of Seismology, 4, 345-356.

Boschi, E., E. Guidoboni, G. Ferrari, D. Mariotti, G. VALENSISE and P. GASPERINI (eds) (2000): Catalogue of Strong Italian Earthquakes, Ann. Geofis., 43 (4), 268.

Chiaraluce, L., C. Chiarabba, C. Collettini, D. PicciniNI and M. CocCO (2007): Architecture and mechanics of an active low-angle normal fault: Alto Tiberina Fault, northern Apennines, Italy, Journal of Geophysical Research, 112, B10310, doi: 10.1029/2007JB005015,

Chimera, G., A. Aoudia, A. Sarao and G.F. Panza (2003): Active tectonics in Central Italy: constraints from surface wave tomography and source moment tensor inversion, Phys. Earth Planet. Inter., 138, 241262.

Della Vedova, B., S. Bellani, G. Pellis and P. Seuarci (2000): Deep Temperatures and Surface Heat-Flow Distribution, in Anatomy of an orogen: the Apennines and adjacent Mediterranean basins, edited by G.B. VAI and L.P. MARTINI (Kluwer Academic Publishers, Dordrecht).
Deschamps, A., R. Scarpa and G. Selvaggi (1989): Analisi sismologica del settore settentrionale dell'Appennino umbro-marchigiano, Atti GNGTS 8th Conference, 1, 9-15.

FeIGL, K.L. and E. DupRE (1998): RNGCHN: a program to calculate displacement components from dislocations in an elastic half-space with applications for modeling geodetic measurements of crustal deformation, revised for Computers and Geosciences.

Galadini, F., P. Galli, I. Leschiutta, G. Monachesi and M. STUCCHI (1999): Active tectonics and seismicity in the area of the 1997 earthquake sequence in central Italy: A short review, Journal of Seismology, 3 (2), 167-175.

Govers, R. and M.J.R. WorTel (1995): Extension of stable continental lithosphere and the initiation of lithosphere scale faults, Tectonics, 14 (4), 1041-1055.

HANSEN, F.D. and N.L. CARTER, (1982): EOS Trans. AGU, 63, 437 .

Meghraoui, M., V. Bosi and T. Camelbeeck (1999): Fault fragment control in the 1997 Umbria-Marche, central Italy, earthquake sequence, Geophys. Res. Lett., 26 (8), 1069-1072.

Mele, G. and E. Sandvol (2003): Deep crustal roots beneath the northern Apennines inferred from teleseismic receiver functions, Earth Planet. Sci. Lett., 211, 69-78.

Olivieri, M. and G. EKSTROM (1999): Rupture depths and source processes of the 1997-1998 earthquake sequence in Central Italy, Bull. Seism. Soc. Am., 89, 305-310.

Pantosti, D., P.M. De Martini, P. Galli, F. Galadini, P. Messina, M. Moro and A. Sposato, (1999): Studi paleosismologici attraverso la rottura superficiale prodotta dal terremoto del 14 ottobre 1997 (Umbria-Marche) Atti $18^{\circ}$ Convegno Annuale del GNGTS, sessione 10 "Forti terremoti dell'area mediterranea".

RANALLI, G., (1995): Rheology of the earth (second edition, Kluwer Academic Publishers, Dordrecht), pp. 432.

Riva, R., A. Aoudia, L.L.A. Vermeersen, R. SAbadini and G.F. PANZA (2000): Crustal versus asthenospheric relaxation and post-seismic deformation for shallow normal faulting earthquakes: the Umbria-Marche (central Italy) case, Geophys. J. Int., 141, F7-F11.

Riva, R.E.M., A. Borghi, A. Aoudia, R. Barzaghi, R. SABADINI and G. F. PANZA (2007): Viscoelastic relaxation and long-lasting after-slip following the 1997 UmbriaMarche (Central Italy) earthquakes, Geophys. J. Int., 169, 534-546, doi: 10.1111/j.1365-246X.2007.03315.x

SABADINI, R. and L.L.A. VERMEERSEN (1997): Influence of lithospheric adn mantle layering on global post-seismic deformation, Geophys. Res. Lett., 24, 2075-2078.

Salvi, S., S. Stramondo, M. Cocco, M. Tesauro, I. HunStad, M. Anzidei, P. Briole, P. Baldi, E. Sansosti, G. Fornaro, R. Lanari, F. Doumaz, A. Pesci and A. GALVANI (2000): Modeling coseismic displacements resulting from SAR interferometry and GPS measurements during the 1997 Umbria-Marche seismic sequence, Journal of Seismology, 4, 479-499.

Zollo, A., Marcucci, S., Milana, G. and P. Capuano (1999): The 1997 Umbria-Marche (central Italy) earthquake sequence: Insights on the mainshock ruptures from near source strong motion records, Geophys. J. Int., 26 (20), 3165-3168. 